\title{
Antimicrobial Ceramic Hybrid Polyethylene Films with Chamomile Extracts for Feed Packaging
}

\author{
Hye Sun Lee and Jeong Ho Chang ${ }^{\dagger}$ \\ Center for Convergence Bioceramic Materials, Korea Institute of Ceramic Engineering and Technology, \\ Cheongju 28160, South Korea
}

(Received April 7, 2017; Revised May 9, 2017; Accepted May 10, 2017)

\begin{abstract}
This work was achieved on the preparation of antimicrobial ceramic hybrid polyethylene films with natural chamomile extracts. The antimicrobial activity and various physicochemical properties of the prepared films were evaluated. Various natural products demonstrated antimicrobial activity. Among them, chamomile extracts showed strong activity and no cytotoxicity rather than that of the natural extracts. Porous ceramic materials were synthesized and demonstrated loading and controlled release of natural antimicrobial extracts. Furthermore, chamomile loaded ceramic hybrid films showed antimicrobial activity that was maintained for over 15 days.
\end{abstract}

Key words : Porous ceramic, Controlled release, Antimicrobial, Hybrid films, Natural product extracts

\section{Introduction}

$\mathrm{T}$ he term feed or fodder refers to materials containing the organic and inorganic nutrients necessary to sustain livestock, for the production of livestock products (such as eggs, milk, meat, feathers, etc.), and for growth, breeding, and feeding processes. ${ }^{1)}$ The ideal feed or fodder has a high level of nutrients for the particular livestock, is innocuous/ nontoxic, with nutrients that do not spoil easily, and is fresh enough so that the digestibility of the nutrients is high. ${ }^{2}$ It is important to ensure that hazardous substances are not included in the feed or fodder that livestock consume, since such substances can affect the health of people. In particular, the contamination of feed or fodder by microorganisms not only directly and indirectly causes diseases in animals, but is also a critical cause of spoiling in feed or fodder, which can result in its ultimately losing its nutritive value. Also, when the feed or fodder are contaminated by fungi types with the ability to exude toxins, acute or chronic poisoning can be caused, resulting in livestock mortality and degraded livestock health, including stunted growth. ${ }^{3,4)}$

Various factors affect whether microorganisms are hazardous in feed or fodder, including the type of feed or fodder, the type of contaminating microorganism, the microorganism count, and whether satisfactory conditions for microorganism habitation exist in the feed or fodder. Such factors can determine whether the feed or fodder will have a harmful effect on livestock health, or on the health of people consuming the livestock products. ${ }^{5,6)}$

\footnotetext{
${ }^{\dagger}$ Corresponding author: Jeong Ho Chang

E-mail : jhchang@kicet.re.kr

Tel : +82-43-913-1501 Fax : +82-43-913-1599
}

Contamination by various microorganisms cannot be prevented, because feed or fodder is handled under conditions where microorganism contamination can occur, including in the production, manufacturing, transportation, and storage of the feed or fodder raw materials. ${ }^{7,8)}$

In order to solve this problem, diverse types of antimicrobial packaging films have been developed, which had a current global market valued at 3.5 trillion Korean won in 2016. Packaging materials for processed foods saw an average annual growth of $3.5 \%$, reaching 300.1 trillion Korean won in $2012 .^{9)}$

In particular, marine feed has a high moisture content compared to other feeds, making it highly susceptible to microorganism growth and rapid spoiling. Antimicrobial packaging film is considered the most definite solution to this problem..$^{10,11)}$

Major spoilage bacteria in marine feed have been reported to include Bacillus methylotrophicus, Bacillus methylotrophicus, Rhodotorula minuta, Debaryomyces sp. ${ }^{12)}$ Research in antimicrobial material development and applications is being carried out to prevent such factors, and recently, studies on natural antifungal substances have been actively pursued, to address the issue of antibiotic abuse. ${ }^{13,14)}$

Research on antibacterial substances from natural sources has been extensively conducted and such studies continue to this day. Antibacterial substances existing in plants are mostly secondary metabolites such as alkaloids, flavonoids, terpenoids, phenolic compounds, quinones, and volatile oils or their derivatives. ${ }^{15)}$ Such antibacterial substances from natural sources are relatively safer compared to antibiotics and synthetic chemotherapeutic agents, and have the added advantage of being less prone to causing resistant bacteria. ${ }^{16)}$ 
However, these antibacterial substances from natural sources do not have the same level of effects compared to synthesized antibiotics, so commercialization of natural antibacterial substances has been slow.

Among such substances, chamomile is the herb most commonly used for medical purposes. Various types of bioactive compounds exist in chamomile and these compounds are typically extracted for use in medicinal and cosmetic products. Approximately 120 secondary metabolites have been identified, whose major components are a-bisabolol, bisabolol oxides A and B as well as chamazulene or azulenesse. $\alpha$ bisabolol oxide A, $\alpha$-bisabolol oxide $\mathrm{B}$, and bisabolone oxide A have been reported to exhibit antibacterial effects. ${ }^{17,18)}$

Porous ceramic materials have uniform porosity and high surface area, and these materials are applied in a variety of fields, as media, supporting structures, for absorption and separation, and as the sensors of functional materials. ${ }^{19,20)}$

Because antibacterial substances extracted from natural sources are organics, they consequently have difficulty withstanding the temperatures of a film fabrication process. As an alternative, porous ceramic materials with high encapsulation efficiency can be used as the media, to inhibit the microorganisms that can occur in the high moisture content feed or fodder, and to enhance moisture absorption efficiency by utilizing the hygroscopic characteristics of the ceramic material. This combination of features may mean that the feed or fodder can be stored for extended periods of time.

In this study, a porous ceramic material was loaded with a natural antibacterial substance and added to polyethylene film, and its physical and antibacterial properties against spoilage bacteria were analyzed, along with its ability to improve the storability of feed or fodder.

\section{Experimental Procedure}

In this study, material synthesis was carried out using a surfactant and silica precursor, and a porous ceramic material with uniform pore size was used as the starting material.

Figure 1 shows a schematic diagram of the porous ceramic material. $4 \mathrm{~g}$ of the surfactant Pluronic P123 from Sigma Aldrich was added to $2 \mathrm{M} \mathrm{HCl}$ and stirred for $24 \mathrm{~h}$. Here, the mixture solution was stirred within a constant-temperature water bath and the solid Pluronic P123 gradually became a transparent solution. The temperature of the bath was $40^{\circ} \mathrm{C}$. Afterwards, $10 \mathrm{~mL}$ of Tetraethyl-orthosilicate was added as the silica precursor, and stirring was carried out for $8 \mathrm{~h}$ so that the reaction could occur consistently.

After adding the silica precursor, formation of the silica particles began. Once the stirring was finished, the solution was poured into a steel pressurizer which was then placed in a high temperature oven, where pressure and heat was applied for $8 \mathrm{~h}$. Then, after cooling to room temperature, distilled water was used for cleaning and the specimens were obtained after filtration and vacuum drying. The dried specimens were then calcinated for $6 \mathrm{~h}$ at $550^{\circ} \mathrm{C}$ to fabricate a porous ceramic material with uniform porosity. A Micromeritics TriStar II-3020 specific surface area analyzer was used to measure the pore size and specific surface area based on the absorption/separation results in nitrogen, and a scanning electron microscope (SM300, Topcon) and transmission electron microscope (JEM-2000EX, JEOL) were employed to observe the particles.

In order to add antibacterial substances extracted from natural sources to the porous ceramic material with uniform porosity, a candidate material with antibacterial properties was selected. The antibacterial effects of its extract on 2 representative fungi strains that appear in fish feed were investigated, by evaluating the minimum inhibitory concentration (MIC) through a Broth dilution assay. Also, concentrations appropriate for use were identified based on safety testing of the antibacterial substances extracted from the natural sources.

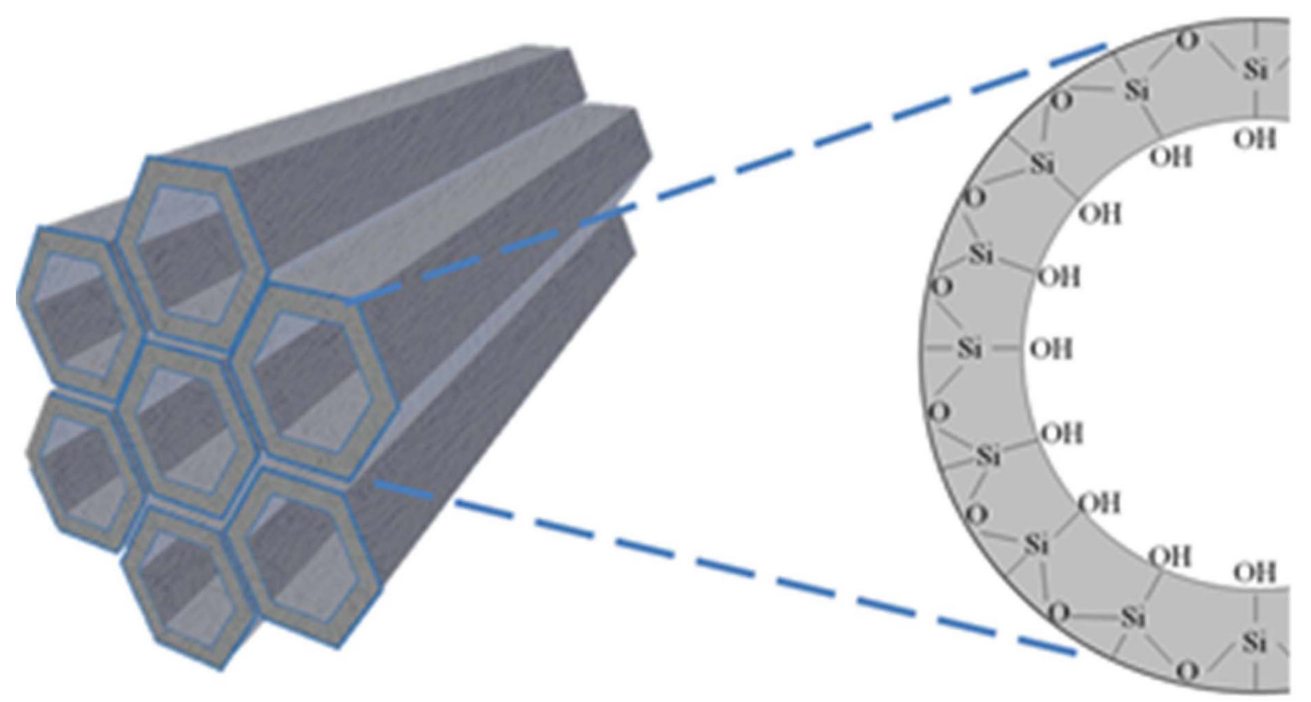

Fig. 1. Schematic structure of porous ceramic materials. 
In this study, an MTT assay was carried out using HaCaT, which is widely used in signal transduction studies, among Keratinocytes, which comprise the human epidermis. This was performed so that other experiments could be conducted using the identified concentration, or for application to other products.

First, the HaCaT cells were seeded into a 96-well plate at $1 \times 10^{5}$ cells $/ \mathrm{ml}$ concentrations and $100 \mu \mathrm{l}$ each followed by $24 \mathrm{~h}$ cultivation in a $37^{\circ} \mathrm{C}, 5 \% \mathrm{CO}_{2}$ incubator. Then, after removing all the culture media, serum-free media were used to process the specimen, diluted at $5 \mu \mathrm{g} / \mathrm{mL}-200 \mu \mathrm{g} / \mathrm{mL}$ to be $100 \mu \mathrm{l}$ per well, followed by $24 \mathrm{~h}$ cultivation. Once finished, the MTT reagent was dissolved to a concentration of $5 \mathrm{mg} / \mathrm{ml}$ using PBS (Phosphate buffer saline), divided into $20 \mu \mathrm{l}$ each, and cultivated for $4 \mathrm{~h}$. After removing all media including the MTT reagent and specimen, $100 \mu \mathrm{l}$ of isopropanol was added to each well, followed by 30 minutes of shaking (dark condition). The sample's absorbance values were then measured using the ELISA reader at $570 \mathrm{~nm}$.

$120 \mathrm{mM}$ of the natural antibacterial substance which exhibited the optimal results among the 4 substances, was loaded into $1 \mathrm{~g}$ of the porous ceramic material. It then underwent thermogravimetric analysis to evaluate its encapsulation efficiency. The thermogravimetric analysis (Product name: TA SDT Q600) was carried out in a nitrogen atmosphere from $20^{\circ} \mathrm{C}$ to $700^{\circ} \mathrm{C}$ at $5^{\circ} \mathrm{C} / \mathrm{min}$. Also, the releasing behavior after the antibacterial substance was loaded into the material was observed, by examining the amount released when the material was exposed to distilled water at room temperature $\left(25^{\circ} \mathrm{C}\right)$. A UV-VIS spectrometer (Product name: JASCO V550) was used to observe the release behavior. The absorbance was measured at the intrinsic wavelength band $(\lambda=245 \mathrm{~nm})$ of the antibacterial substance extracted from natural sources using the JASCO V550 for the range of $200 \mathrm{~nm}$ to $300 \mathrm{~nm}$.

To prepare the antibacterial substance loaded ceramic material composite feed or fodder packaging film, a porous ceramic material containing a pellet form master batch was prepared, and the film was then fabricated by mixing the master batch and resin at a weight ratio of 1:9. The organic material content of the entire film was $3 \%$ and the thickness of the film, manufactured by the Blown extrusion production method, was $3 \mu \mathrm{m}$. Right after extrusion, a bag making machine was used to produce envelope shaped products.

Experiments were carried out to assess the feed preservation using the antibacterial material loaded ceramic composite packaging film, in comparison to conventional packaging film. Changes in the feed that were preserved in a sealed state at room temperature, and the feed stored using the selected antibacterial material added packaging material, were observed with the naked eye.

\section{Result and Discussion}

Figure 2(a) shows scanning electron microscope images used to observe the porous ceramic material particle shapes, and transmission electron microscope images used to observe the uniform porosity. It was determined that the a)
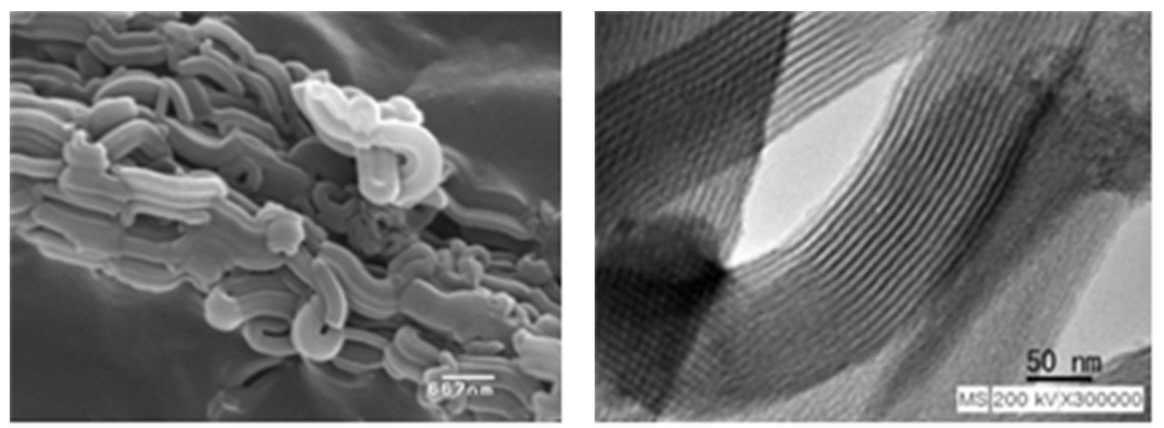

b)

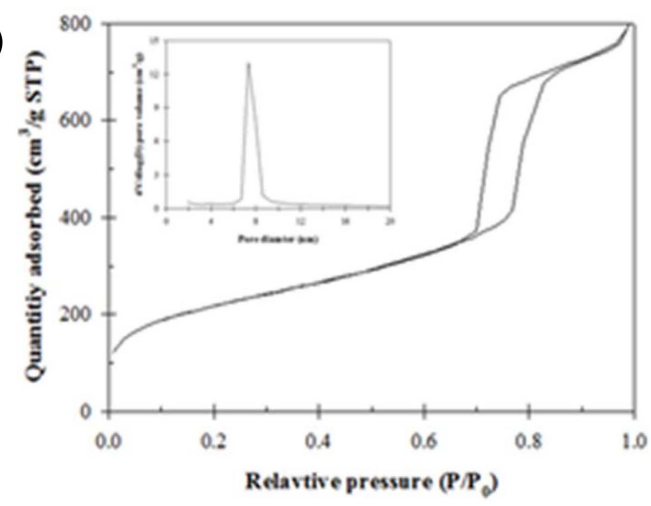

\begin{tabular}{ccc}
\hline $\begin{array}{c}\text { BET } \\
\left(\mathbf{m}^{2} / \mathrm{g}\right)\end{array}$ & $\begin{array}{c}\text { Pore volume } \\
\left(\mathrm{cm}^{3} / \mathrm{g}\right)\end{array}$ & $\begin{array}{c}\text { Average pore } \\
\text { diameter }(\mathbf{n m})\end{array}$ \\
\hline 753.9 & 1.29 & 6.66 \\
\hline
\end{tabular}

Fig. 2. (a) SEM and TEM images of porous ceramic materials, (b) Nitrogen adsorption-desorption isotherms and pore-size distribution of porous ceramic materials. 
Table 1. Antimicrobial Evaluation of the Various Extracts from Natural Sources

\begin{tabular}{|c|c|c|c|c|}
\hline \multicolumn{5}{|c|}{ Rhodotorula minuta } \\
\hline No & Samples & Concentration (\%) & Inhibitory zone (mm) & Images \\
\hline \multirow{3}{*}{1} & & 0.5 & 10 & \\
\hline & Phenoxyethanol (Control) & 1.0 & 12 & \\
\hline & & 2.0 & 15 & \\
\hline \multirow{3}{*}{2} & & 0.5 & 11 & \\
\hline & Arctii Fructus & 1.0 & 11 & \\
\hline & & 2.0 & 11 & \\
\hline \multirow{3}{*}{3} & & 0.5 & 11 & \\
\hline & Agrimonia pilosa Ledeb & 1.0 & 11 & \\
\hline & & 2.0 & 11 & \\
\hline \multirow{3}{*}{4} & & 0.5 & 11 & \\
\hline & Moutan Cortex Radicis & 1.0 & 11 & \\
\hline & & 2.0 & 11 & \\
\hline \multirow{3}{*}{5} & & 0.5 & 12 & \\
\hline & Chamomile & 1.0 & 13 & \\
\hline & & 2.0 & 14 & \\
\hline
\end{tabular}

porous ceramic material particles were in long bundles of $1.5-2 \mu \mathrm{m}$. The transmission electron microscope image revealed that the pore sizes were uniform, at about $6 \mathrm{~nm}$. Fig. 2(b) shows the absorption-desorption isothermal curve, pore size, and specific surface area measurement analysis results, that were used to analyze the pore distribution characteristics.

The Type IV graph can be observed with a distribution curve of $2-20 \mathrm{~nm}$ mesopores. Also, an average pore size of $6.6 \mathrm{~nm}$ and a specific surface area of $753.9 \mathrm{~m}^{2} / \mathrm{g}$ were observed. Based on these findings, it was concluded that a porous ceramic material with a $6.6 \mathrm{~nm}$ pore size would be fabricated.

Table 1 and Fig. 3 shows the antifungal property results of the natural source antibacterial substance, and the cytotoxicity evaluation result of the substance with the optimal antifungal characteristics. Phenoxyethanol, Arctii Fructus, Agrimonia pilosa, and Moutan Radicis Cortex, which have been reported to exhibit antimicrobial effects, were selected, diluted to $0.5,1$, and $2 \%$ solutions, and smeared on a disc to be placed on the Rhodotorula minuta strain, which was applied to a corpuscle agar medium, where cultivation was conducted for 5 days. Then, the area of the transparent

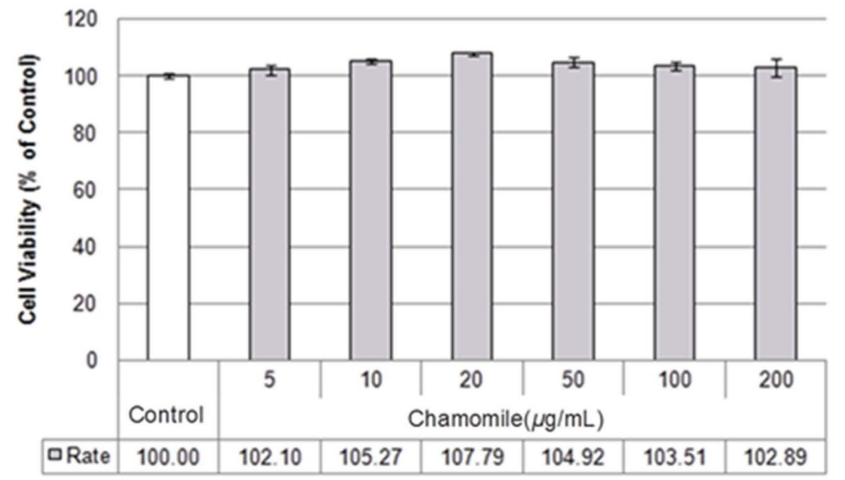

Fig. 3. MTT assay of natural chamomile extracts.

growth inhibition zone formed was measured, which showed that the inhibition zones of the Arctii Fructus, Agrimonia pilosa, and Moutan Radicis Cortex were $11 \mathrm{~mm}$. That value did not change with different concentrations.

On the other hand, the chamomile showed an antibacterial effect similar to the antimicrobial Phenoxyethanol used as the control group. Additionally, it was found that the antimicrobial effect increased according to the concentration. Through these results, it was observed that chamomile 
(a)

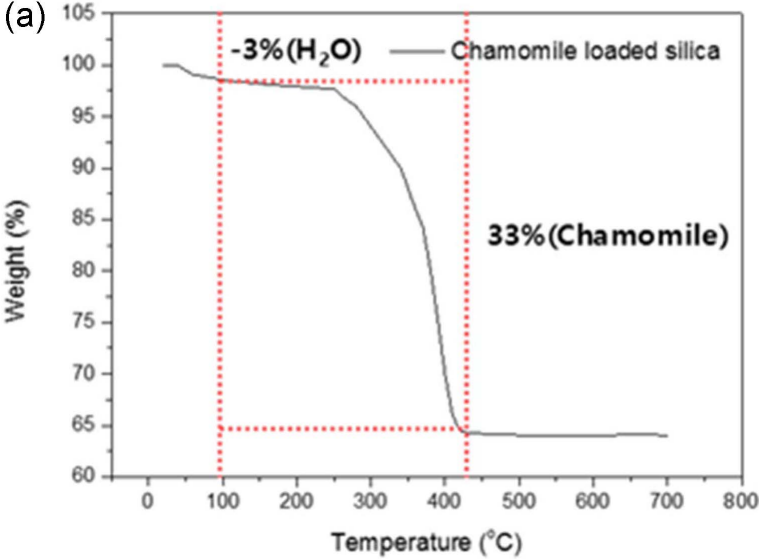

(b)

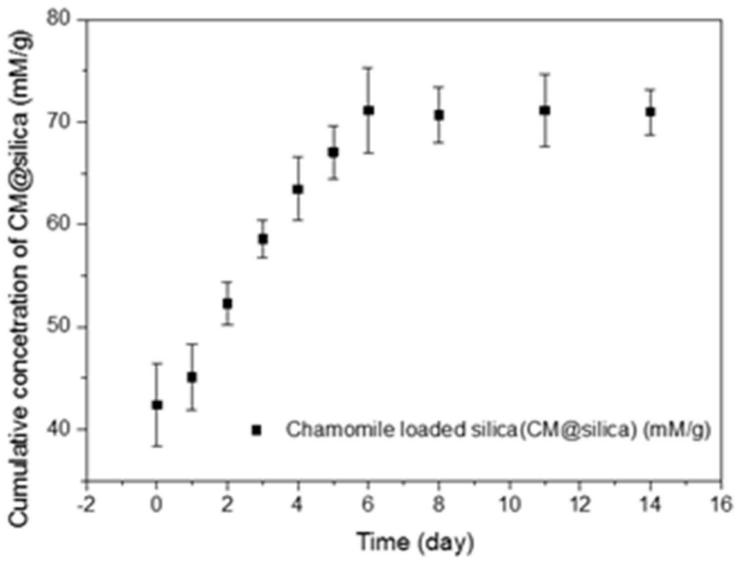

Fig. 4. (a) TGA analysis and (b) release profiles of chamomile loaded porous ceramic materials.

exhibited antibacterial effects, and chamomile was subsequently used to assess its cytotoxicity.

When a mortality rate is greater than $20 \%$ relative to the control group with unprocessed specimens, it is determined to have toxicity, and this was reflected in the concentrations chosen for later experiments. The cytotoxicity evaluation for chamomile conducted in this study revealed cell viabilities above $100 \%$ within the experiment concentration range. It was determined that cytotoxicity was not exhibited.

Cell viability $(\%$ of control $)=$

(Specimen absorbance / Control group absorbance) $\times 100$

Figure 4(a) shows the thermogravimetric analysis results, used to identify the encapsulation efficiency after loading $120 \mathrm{mM}$ of functional substance into the porous ceramic material used in this study. It was observed that there was a mass change of approximately $33 \%$ in the temperature range from $100^{\circ} \mathrm{C}$ to $400^{\circ} \mathrm{C}$, where the moisture in the antibacterial organic materials was removed. Through this, it was determined that the antibacterial substance extracted from natural sources had been loaded to $33 \%$ in the porous ceramic material.

Figure 4(b) shows the release behavior of the loaded antibacterial substance. The initial concentration when loaded by $33 \%$ was $42.42 \mathrm{mM} / \mathrm{G}$, and the release concentration relative to the loaded amount was $26.73 \mathrm{mM} / \mathrm{g}$. This value converted to percentage resulted in a release of $64.81 \%$.

A PE film containing the control, using the fish feed with high moisture content, and $3 \%$ of the chamomile added porous silica (CM@silica) was fabricated with a concentration of $42.42 \mathrm{mM} / \mathrm{g}$. Then the feed or fodder was packaged, and the film's efficiency was observed using the naked eye during storage.

For the case of EP (soft extruded pellet), the moisture content ranged between $20-30 \%$ when stored at room temperature or refrigerated. Also, the expiration date did not exceed 15 days, and the gradual appearance of bacteria was observed after 10 days for the conventional soft EP feed as shown in Fig. 5. After 15 days, the growth of the mold could

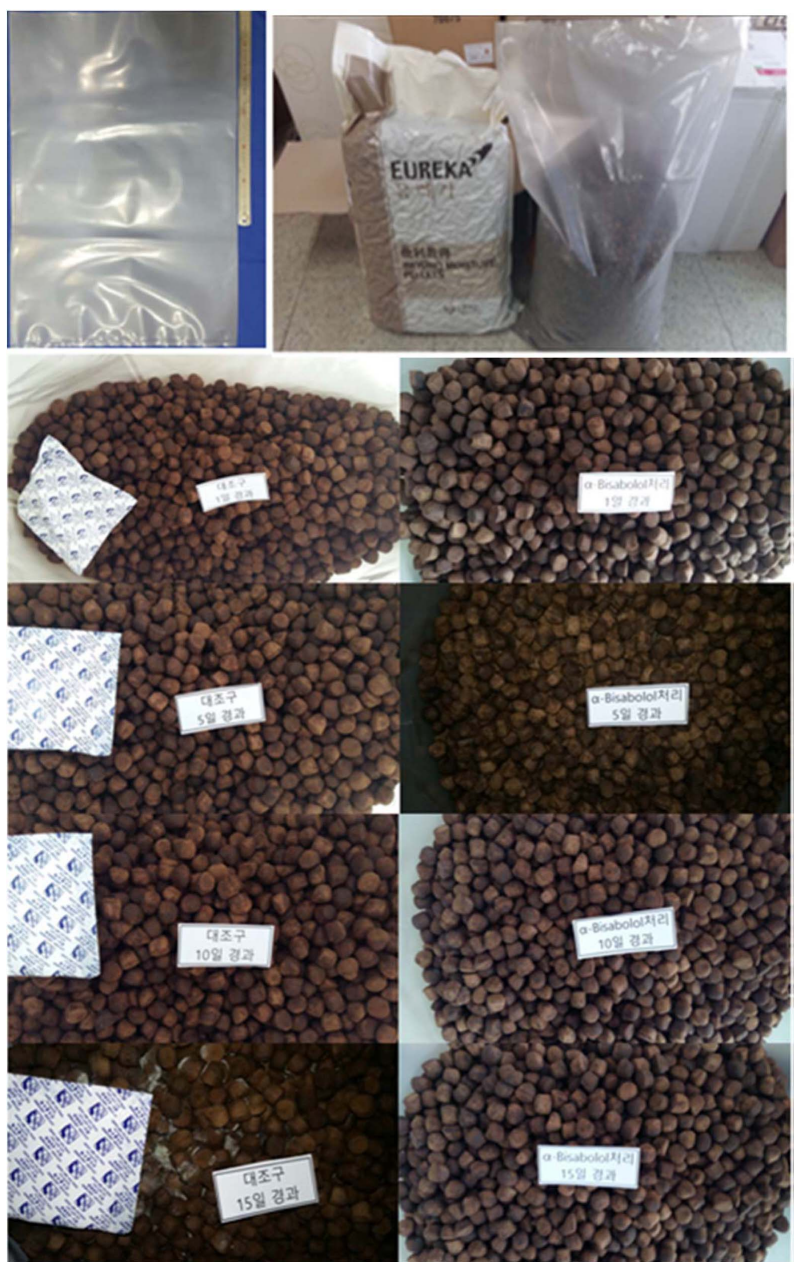

Fig. 5. Visual inspection of the efficiency changes in packaging types.

be observed with ease.

For the chamomile added packaging material, no visible mold contamination like that of the control could be observed. Table 2 shows the result of the feed preservation experiment, using the chamomile processed feed packaging 
Table 2. Comparison of Total Microbial Counts Changes between Control and Packaging Films Containing Chamomile Extracts as a Function of Storage Time

\begin{tabular}{ccccc}
\hline & \multicolumn{4}{c}{ Storage time (day) } \\
\cline { 2 - 5 } & 1 & 5 & 10 & 15 \\
\hline $\begin{array}{r}\text { Control } \\
(\mathrm{cfu} / \mathrm{g})\end{array}$ & $2.3 \times 10^{4}$ & $2.4 \times 10^{5}$ & $4.9 \times 10^{5}$ & $2.5 \times 10^{7}$ \\
\hline $\begin{array}{r}\text { Sample } \\
(\mathrm{cfu} / \mathrm{g})\end{array}$ & $2.3 \times 10^{4}$ & $1.2 \times 10^{5}$ & $3.9 \times 10^{5}$ & $3.2 \times 10^{5}$ \\
\hline
\end{tabular}

material and the control for a regular microbial count. It was found that the chamomile applied case did not allow an increase in the microbial count, and the allowable microorganism threshold of $5.0 \times 10^{5} \mathrm{cfu} / \mathrm{g}$ was not exceeded. But because the microorganism count exceeded this threshold after 15 days for the control, it was not suitable for use as feed or fodder.

Through this study, the chamomile processed feed packaging material was demonstrated to increase the feed expiration date by approximately 5 days, compared to the conventional packaging.

\section{Conclusions}

In this study, low density polyethylene and porous ceramic material loaded with antibacterial substances extracted from natural sources were combined to manufacture a functional film with antibacterial effects, and the properties of the fabricated film were investigated. The porous ceramic material had an average particle size of $1.5-2 \mu \mathrm{m}$ and a uniform porous structure, with pore sizes of $5 \mathrm{~nm}$. This gave the material outstanding antibacterial substance loading capacity.

Among various natural substances with reported antimicrobial effects, chamomile was selected as the antibacterial substance, because it can inhibit a fungus strain with an efficiency similar to that of a control synthetic antimicrobial agent.

The thermogravimetric analysis result of the chamomile loaded porous ceramic material showed a loading of approximately 33\%, and the MTT assay analysis result revealed no cytotoxicity with a cell vitality of above $100 \%$, within the experiment concentration range.

The release characteristic of the antibacterial substance loaded ceramic material at room temperature was investigated and found to have a high release behavior of $64.81 \%$ relative to the initial loading concentration.

Also, the duration of feed preservation, and the allowable microorganism value were studies, using both conventional low density feed packaging material and the antibacterial substance loaded ceramic material hybrid packaging film. The results showed that the storage period can be extended by over 5 days relative to the conventional film.

This study determined that that the material developed in this study exhibited the ability to inhibit the problem of spoilage by fungi in conventional marine feed.

\section{Acknowledgments}

"This work was supported by the Core Convergence Technology Development Program of the Korea Industrial Technology Association (KOITA) funded by the Ministry of Science, ICT and Future Planning in 2015.”

\section{REFERENCES}

1. A. Cockburn, G. Brambilla, M. L. Fernandez, D. Arcella, L. R. Bordajandi, B. Cottrill, C. V. Peteghem, and J. L. Dorne, "Nitrite in Feed: From Animal Health to Human Health," Toxicol. Appl. Pharmacol., 270 [3] 209-17 (2013).

2. L. P. Reynolds, J. J. Ireland, J. S. Caton, D. E. Bauman, and T. A. Davis, "Commentary on Domestic Animals in Agricultural and Biomedical Research: An Endangered Enterprise," J. Nutri., 139 [3] 427-28 (2009).

3. J. P. F. D'mello, C. M. Placinta, and A. M. C. Macdonald, "Fusarium mycotoxins: A Review of Global Implications for Animal Health, Welfare and Productivity," Anim. Feed Sci. Technol., 80 [3], 183-205 (1999).

4. K. J. Yi, J. S. Yeon, J. H. Kim, S. C. Kim, H. I. Moon, C. O. Jeon, S. S. Lee, D. W. Kim, and S. K. Kim, "Microbiological and Chemical Changes of Complete Feed during Spoilage (in Korean)," J. Life Sci., 25 [10] 1148-55 (2015).

5. I. Bartov, N. Paster, and N. Lisker, "The Nutritional Value of Moldy Grains for Broiler Chicks," Poult. Sci., 61 [11] 2247-54 (1982).

6. L. Kung Jr, A. C. Sheperd, A. M. Smagala, K. M. Endres, C. A. Bessett, N. K. Ranjit, and J. L. Glancey, "The Effect of Preservatives Based on Propionic Acid on the Fermentation and Aerobic Stability of Corn Silage and a Total Mixed Ration," J. Dairy Sci., 81 [5] 1322-30 (1998).

7. C. Magnoli, C. Hallak, A. Astoreca, L. Ponsone, S. M. Chiacchiera, G. Palacio, and A. Dalcero, "Surveillance of Toxigenic Fungi and Ochratoxin A in Feedstuffs from Cordoba Province," Vet. Res. Commun., 29 [5] 43-5 (2005).

8. W. B. Shim, S. B. Cho, N. M. K. Shim, J. E. Jung, and D. H. Jung, "Studies on the Control of Mold and its Toxin in Indirect Foods (Animal Feeds) by Radiation Technology (in Korean)," Korea Atomic Energy Research Institute, 2015.

9. K. S. Seo, S. B. Kim, and M. S. Shin, "2015 Food industry analysis report (in Korean)," Korea Health Industry Development Agency, December 2015.

10. M. Y. Choi, E. J. Choi, E. Lee, T. J. Rhim, B. C. Cha, and H. J. Park, "Antimicrobial Activites of Pine Needle (Pinus Densiflora Seib et Zucc.) Extract (in Korean)," Kor. J. Appl. Microbiol. Biotechnol., 25 293-97 (1997).

11. J. D. Jung and S. H. Cho, "Quality Control of Natural Antimicrobial Agents for the Preservation of Swine Feed (in Korean)," J. Agric \& Life Sci., 37 [4] 85-92 (2003).

12. J. H. Heo, M. H. Jung, M. H. Cho, G. H. Kim, K. C. Lee, J. H. Kim, and T. S. Jung, "The Study on Fish Diseases with Reference to Bacterial Susceptibility to Antibiotics in the Southern Area of Kyeognam (in Korean)," J. Vet. Clin., 19 19-22 (2002). 
13. S. E. Kim, G. H. Choi, K. M. Shim, J. C. Kim, J.C. Yo, S. S. Cho, and S. S. Kang, "Effects of Probiotic CS-32 as a Feed Additive on Growth Performance of Broiler Chickens (in Korean)," J. Biomed. Res., 14 [3] 170-76 (2013).

14. S. J. Park and S. O. Yoo, "Effects of Supplemention of Antibiotic, Probiotic and Yeast Culture on Performance and Meat Quality in Broiler Chicks (in Korean)," Kor. J. Poult. Sci., 27 203-8 (2000).

15. A. R. Kim, D. K. Kim, T. H. Byun, E. J. Jo, E. W. Lee, H. J. Kwon, B. W. Kim, T. H. Kim, K. B. Lee, and Y. M. Kim, "Antibacterial Activity of Herbal Medicine Extracts against Edwardsiella Tarda (in Korean)," Kor. J. Food Pres., 18 [1] 87-90 (2011).

16. A. L. Mahmoud, "Antifungal Action and Antiaflatoxigenic Properties of Some Essential Oil Constituents," Lett. Appl. Microbiol., 19 [2] 110-13 (1994).
17. J. K. Srivastava, E. Shankar, and S. Gupta, "Chamomile: A Herbal Medicine of the Past with Bright Future," Mol. Med. Rep., 3 [6] 895-901 (2010).

18. H. S. Baek, S. K. Kang, Q. S. Auh, Y. H. Chun, and J. P. Hong, "Effect of Antibacterial Effects of Myrrh, Rhatany, Chamomilla against to Oral Microorganisms," Kor. J. Oral Med., 38 [4] 299-312 (2013).

19. H. S. Lee, W. H. Kim, J. H. Lee, D. J. Choi, Y. K. Jeong, and J. H. Chang, "Transition Metal-Chelating Surfactant Micelle Templates for Facile Synthesis of Mesoporous Silica Nanoparticles," J. Solid State Chem., 185 89-94 (2012).

20. D. Zhao, J. Feng, Q. Huo, N. Melosh, G. H. Fredrickson, B. F. Chmelka, and G. D. Stucky, "Triblock Copolymer Syntheses of Mesoporous Silica with Periodic 50 to 300 Angstrom Pores," Science 279 [5350] 548-52 (1998). 